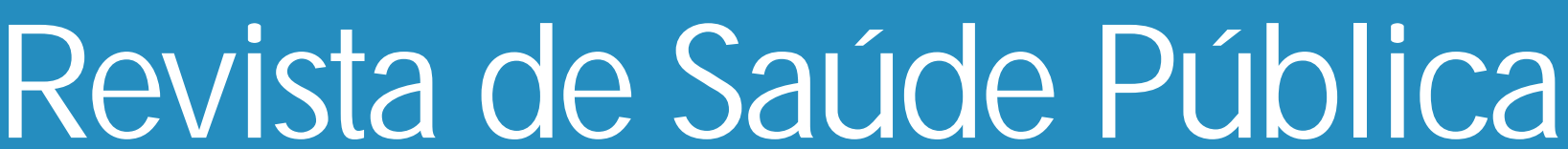

$\begin{array}{lllllll}\mathbf{O} & \mathbf{U} & \mathbf{R} & \mathbf{N} & \mathbf{A} & \mathbf{L}\end{array}$

$0 \mathbf{F}$

$\mathbf{P} \mathbf{U}$

$B \quad L \quad$ I C

H E A L T

\title{
Relação entre patogenicidade do Schistosoma mansoni em camundongos e susceptibilidade do molusco vetor. IV - Infecciosidade dos miracidios
}

\section{Relationship between the pathogenicity of Schistosoma mansoni in mice and the susceptibility of the vector mollusk. IV - Infectiousness of the miracídia}

Eliana Maria Zanotti-Magalhães, Luiz Augusto Magalhães e José Ferreira de Carcalho Departamento de Parasitologia do Instituto de Biologia da U niversidade Estadual de Campinas (UN ICAMP). Campinas, SP - Brasil (E.M.Z.M., L.A.M .), D epartamento de Matemática, Estatística e Ciência Científica da U N ICAM P. Campinas, SP (J.F.C.) 


\title{
Relação entre patogenicidade do Schistosoma mansoni em camundongos e susceptibilidade do molusco vetor. IV - Infecciosidade dos miracidios*
}

\section{Relationship between the pathogenicity of Schistosoma mansoni in mice and the susceptibility of the vector mollusk. IV - Infectiousness of the miracídia}

\author{
Eliana Maria Zanotti-Magalhães, Luiz Augusto Magalhães e José Ferreira de Carcalho \\ Departamento de Parasitologia do Instituto de Biologia da Universidade Estadual de Campinas \\ (U NICAM P). Campinas, SP - Brasil (E.M.Z.M., L.A.M.), Departamento de Matemática, Estatística e \\ Ciência Científica da U NICAMP. Campinas, SP (J.F.C.)
}
Objetivo Comparar a capacidade de infecção de miracídios das linhagens BH e SJ de $S$. mansoni, obtidos de camundongos infectados com cercárias oriundas de Biomphalaria glabrata e B. tenagophila, selecionadas geneticamente para a susceptibilidade, com miracídios obtidos de camundongos infectados com lar- vas procedentes de moluscos não selecionados.

Material e Método

Progenies de S. mansoni foram obtidas das passagens sucessivas pelos moluscos selecionados, obtendo-se assim gerações de miracídios selecionados. A seleção de $B$. glabrata e $B$. tenagophila foi realizada através da autofecundação dos moluscos susceptíveis, frente às respectivas linhagnes BH e SJ do trematódeo. Foram obtidas 5 gerações de moluscos $\left(\mathrm{P}_{\text {a }} \mathrm{F}_{4}\right)$. Os testes de infecciosidade dos miracídios foram realizados utilizando-se 10 larvas e a susceptibilidade verificada após 30 dias e durante 3 meses, através da detecção da eliminação de cercárias.

Resultados Evidenciou-se que a susceptibilidade de moluscos selecionados, confrontada
com as respectivas linhagens simpátricas, não foi alterada pelo processo de
selecão das linhagens do trematódeo, porém miracídios $\mathrm{BHF}_{4}$ foram mais
infectantes frente a $B$. glabrata não selecionada do que miracídios BHP. A sele-
ção de $B$. glabrata propiciou sua infecção de modo semelhante com miracídios
$\mathrm{BHP}$, SJP e $\mathrm{BHF}_{3}$. Esses moluscos não apresentaram a mesma capacidade de
infecção frente a miracídios alopátricos selecionados $\left(\mathrm{SJF}_{4}\right)$. A passagem su-

* Pesquisa subvencionado pela Financiadora de Estudos e Projetos (Processo nº 410427/89-6 e pela Fundação de Amparo à Pesquisa do Estado de São Paulo/FAPESP (Processo n ${ }^{\circ}$ 43/81/0417-0).

Correspondência para/Correspondence to: Eliana M. Zanotti-Magalhães - Caixa Postal 6109 - Cidade Universitária Barão Geraldo - 13083-970

Campinas, SP - Brasil. E-mail: luiz @ correionet.com.br.

Edição subvencionada pela FAPESP (Processo 97/09815-2).

Recebido em 27.12.1996. Reapresentado em 30.4.1997. Aprovado em 4.6.1997. 
Conclusões

\section{Material and Method}

Results

Conclusion cessiva do S. mansoni SJ em B. tenagophila selecionada ajustou essa linhagem para essa espécie de molusco. B. tenagophila nunca foi susceptível à linhagem $\mathrm{BH}$, mesmo utilizando moluscos e trematódeos selecionados. A susceptibilidade/infecciosidade do binomio B. tenagophila - linhagem SJ só foi alterada pelo processo de seleção do molusco.

Como miracídios $\mathrm{BH}$ selecionados infectaram, de forma mais intensa, $B$. glabrata não selecionada do que miracídios $\mathrm{BH}$ não selecionados, conclui-se que a maior patogenicidade do S. mansoni, oriundo de moluscos mais susceptíveis, implica maior capacidade de infecção desses miracídios.

Schistosoma mansoni, patogenicidade. Biomphalaria.

\section{Abstract}

The infection ability of miracidia of BH and SJ strains of $\mathrm{S}$. mansoni, obtained from mice infected with cercariae taken from Biomphalaria glabrata and Biomphalaria tenagophila, genetically selected for susceptibility is compared with the infection ability of miracidia obtained from mice infected with larvae from non-selected mollusks.

Progeny of S. mansoni resulting from successive infections of selected mollusk sproduced various generations of selected miracidia. Selecion of B. glabrata and $\mathrm{B}$. tengophila was carried out by autofertilization of mollusks susceptible to the BH and SJ strains of S. mansoni. Five generations of mollusks (from parental down to F4), were used in the experiment. Tests for the infectiousness of the miracidia used 10 larvae; susceptibility was checked starting on day 30 after infection, for 90 days, through observation for the presence of cercariae.

The results showed that susceptibility of the selected mollusks in the face of the respective sympatric strains was not altered by the selection process of $\mathrm{S}$. mansoni. However F4 miracidia of the BH strain were more infectant for non-selected $\mathrm{B}$. glabrata than parental miracidia of the same strain. Miracidia of $B H$ and SJ strains, parental generation, and BH strain, F3 generation, showed the same infectiousness in selected B. glabrata. Nevertheless, these mollusks had distinct infection rates from allopatric selected miracidia (SJ strain, F4 generation). The generation of successive infections of $S$. mansoni SJ in selected $\mathrm{B}$. tenagophila resulted in the adaptation of the worm strain to the species of mollusk. B. tenagophila was never susceptible to the BH strain, even when selected mollusks and trematodes were employed. The susceptibility/infectiousness of the pair B. tenagophila-SJ S. mansoni strain was only changed by the selection process of the mollusks.

As non-selected B. glabrata were more intensively infected by selected $\mathrm{BH}$ miracidia than by non-selected BH miracidia, one is led to surmise that the greater pathogenicity of $\mathrm{S}$. mansoni from susceptible mollusks implies the greater infection ability of these miracidia.

\section{Schistosoma mansoni. Biomphalaria.}




\section{INTRO DUÇÃO}

Embora a patogênese da esquistossomose mansônica esteja relacionada com a intensidade da deposição de ovos pelo trematódeo nos tecidos do hospedeiro vertebrado, Saoud ${ }^{16}$ (1966) não evidenciou relação entre o número de ovos produzidos e a virulência do Schistosoma mansoni, sugerindo que a maior virulência poderia ser decorrência da mais ampla distribuição de ovos nos órgãos. Maior número de ovos no tecido hepático e maior mortalidade dos hospedeiros vertebrados em camundongos infectados com cercárias oriundas de Biomphalaria glabrata e Biomphalaria tenagophila selecionadas geneticamente para o caráter susceptibilidade (Zanotti-Magalhães e col. ${ }^{21,22}$, 1993, 1995).

Conceição e Coura ${ }^{4}$ (1983), estudando o comportamento em B. glabrata infectadas com amostras de $S$. mansoni isoladas de pacientes portadores de diferentes formas clínicas de esquistossomose, verificaram a produção de maior número de cercárias e maior mortalidade dos caramujos, quando as amostras foram provenientes de pacientes com a forma hepatointestinal e hepatosplênica.

Testes de infecciosidade de miracídios de S. mansoni, procedentes de ovos colhidos nas fezes e de ovos obtidos de granulomas hepáticos de camundongos, indicaram que a reação inflamatória em torno do ovo observada nos granulomas não foi prejudicial a viabilidade dos miracídios, sendo a taxa de infecção dos moluscos equivalente entre os dois grupos. Embora o período pré-patente de eliminação de cercárias tenha sido maior nos moluscos infectados com miracídios oriundos de granulomas hepáticos, a quantidade de cercárias produzidas nesses moluscos foi três vezes maior do que em moluscos expostos a miracídios obtidos das fezes (Zanotti-Magalhães e col. $\left.{ }^{18}, 1988\right)$. Teriam os miracídios obtidos de camundongos infectados com cercárias oriundas de moluscos selecionados geneticamente para o cárater susceptibilidade, terem maior poder de infecção do que aqueles obtidos a partir de camundongos experimentalmente infectados com $S$. mansoni obtidos de moluscos não selecionados geneticamente para a susceptibilidade?

Em trabalhos publicados anteriormente (ZanottiMagalhães e col. ${ }^{20,21,22}, 1991,1993$ e 1995) foram apresentados resultados que ressaltam maior patogênese do $S$. mansoni em camundongos infectados com cercárias, provenientes de moluscos selecionados geneticamente para o caráter susceptibilidade.
Estudo da atração miraxonal, utilizando Biomphalaria tenagophila selecionada geneticamente para o caráter susceptibilidade, mostrou que o fato de se terem utilizados miracídios provenientes de população de trematódeo mantido em moluscos selecionados para o caráter susceptibilidade por várias gerações, não produziu interferência no processo quimiotáxico (Zanotti-Magalhães e col. ${ }^{19}, 1991$ ).

O objetivo do presente trabalho foi comparar a capacidade de infecção de miracídios das linhagens BH e SJ de $S$. mansoni, obtidos através de passagens sucessivas em $B$. glabrata e $B$. tenagophila, selecionadas geneticamente para a susceptibilidade, com miracídios obtidos de camundongos infectados com cercárias oriundas de moluscos não selecionados.

\section{MATERIAL E MÉTO DO}

B. glabrata e B. tenagophila foram selecionadas geneticamente através da autofecundação dos moluscos que se mostraram susceptíveis, respectivamente, às linhagens BH e SJ de S. mansoni (Zanotti-Magalhães e col. ${ }^{20}$, 1991). Através da autofecundação dos moluscos susceptíveis, foram obtidas cinco progenies para cada espécie de molusco (gerações $\mathrm{P}$ a $\mathrm{F}_{4}$ ). Paralelamente à seleção de moluscos, foram obtidas progenies de $S$. mansoni oriundas das passagens sucessivas nos moluscos selecionados.

Foram também utilizados moluscos não selecionados, de ambas as espécies, expostos ao trematódeo não selecionado, denominados geração P.

Os planorbídeos foram expostos a 10 miracídios e após 30 dias foram examinados semanalmente, durante 3 meses, procurando-se detectar a eliminação de cercárias.

Geração P (não selecionada) de molusco e trematódeo e geração selecionada $\mathrm{F}_{3} \mathrm{eF}_{4}$ de moluscoe gerações selecionadas $\mathrm{F}_{3}, \mathrm{~F}_{4}$ e $\mathrm{F}_{5}$ de $S$. mansoni foram utilizadas no planejamento experimental (Zanotti-Magalhães e col. ${ }^{20}, 1991$ ).

Foram formados 16 grupos experimentais:

1. B. glabrata selecionada exposta a miracídios BH não selecionados.

2. B. glabrata selecionada exposta a miracídios BH selecionados.

3. B. glabrata selecionada exposta a miracídios SJ não selecionados.

4. B. glabrata selecionada exposta a miracídios SJ selecionados.

5. B. glabrata não selecionada exposta a miracídios $\mathrm{BH}$ não selecionados.

6. B. glabrata não selecionada exposta a miracídios $\mathrm{BH}$ selecionados.

7. B. glabrata não selecionada exposta a miracídios SJ não selecionados.

8. B. glabrata não selecionada exposta a miracídios SJ selecionados.

Foram formados 8 grupos semelhantes utilizando-se moluscos B. tenagophila. 
Em cada prova do experimento, tomaram-se moluscos de uma espécie e geração, que foram aleatoriamente separados em dois grupos, para serem submetidos às distintas infecções, de acordo com o grupo. Os resultados do experimento foram constituídos pelos números de moluscos infectados e não infectados de cada grupo. Para testar a hipótese de não associação (independência) entre a geração do trematódeo e a resposta, usou-se o teste estatístico quiquadrado de verossimilhança (estatística de Wald). Os níveis de significância estão indicados nas tabelas.

\section{RESULTAD O S}

Miracídios de S. mansoni das linhagens BH e SJ, obtidos ou não de linhagens mantidas em moluscos selecionados geneticamente para o caráter susceptibilidade, apresentaram grau de infecciosidade semelhante quando expostos a moluscos simpátricos selecionados (Tabela 1).

Tabela 1 - Infecciosidade de miracídios de S. mansoni das linhagens BH e SJ selecionados e não selecionados frente a moluscos selecionados simpátricos.

\begin{tabular}{|c|c|c|c|c|}
\hline Molusco/G eração & $\begin{array}{c}\text { Linhagem e } \\
\text { Geração do S. } \\
\text { mansoni }\end{array}$ & $\begin{array}{l}\text { Número de } \\
\text { moluscos } \\
\text { utilizados }\end{array}$ & $\begin{array}{c}\text { Número de } \\
\text { moluscos } \\
\text { positivos }\end{array}$ & $\begin{array}{c}\text { Taxa de } \\
\text { infecção } \\
(\%)\end{array}$ \\
\hline $\begin{array}{l}\text { B. glabrata } \mathrm{F}_{3} \\
\text { B. glabrata } \mathrm{F}^{3} \\
\text { B. tenagophila } \mathrm{F}_{3} \\
\text { B. tenagophila } \mathrm{F}_{3}\end{array}$ & $\begin{array}{l}\mathrm{BHF}_{3} \\
\mathrm{BHP}^{3} \\
\mathrm{SJF}_{3} \\
\mathrm{SJP}^{3}\end{array}$ & $\begin{array}{l}19 \\
27 \\
52 \\
70\end{array}$ & $\begin{array}{l}14 \\
16 \\
35 \\
53\end{array}$ & $\begin{array}{l}74(\mathrm{a}) \\
59(\mathrm{a}) \\
67(\mathrm{~b}) \\
76(\mathrm{~b})\end{array}$ \\
\hline
\end{tabular}

(a) diferença não significativa $(p=0,308)$.

(b) diferença não significativa $(p=0,307)$

Tabela 2 - Infecciosidade de miracídios de S. mansoni das linhagens BH e SJ não selecionados frente a moluscos simpátricos e alopátricos selecionados.

\begin{tabular}{lcccc}
\hline M olusco/Geração & $\begin{array}{c}\text { Linhagem e } \\
\text { Geração do S. } \\
\text { mansoni }\end{array}$ & $\begin{array}{c}\text { Número de } \\
\text { moluscos } \\
\text { utilizados }\end{array}$ & $\begin{array}{c}\text { Número de } \\
\text { moluscos } \\
\text { positivos }\end{array}$ & $\begin{array}{c}\text { Taxa de } \\
\text { infecção } \\
\text { (\%) }\end{array}$ \\
\hline B. glabrata F & BHP & 16 & 9 & 56 (a) \\
B. glabrata F & SJP & 16 & 10 & 63 (a) \\
B. tenagophila F & BHP & 27 & 0 & 0 (b) \\
B. tenagophila F 4 & SJP & 27 & 21 & 78 (b) \\
\hline
\end{tabular}

(a) diferença não significativa $(p=0,719)$.

(b) diferença significativa $(p=0,000)$

Tabela 3 - Infecciosidade de miracídios de S. mansoni das linhagens BH e SJ selecionados frente a moluscos simpátricos e alopátricos selecionados.

\begin{tabular}{lcccc}
\hline M olusco/Geração & $\begin{array}{c}\text { Linhagem e } \\
\text { Geração do S. } \\
\text { mansoni }\end{array}$ & $\begin{array}{c}\text { Número de } \\
\text { moluscos } \\
\text { utilizados }\end{array}$ & $\begin{array}{c}\text { Número de } \\
\text { moluscos } \\
\text { positivos }\end{array}$ & $\begin{array}{c}\text { Taxa de } \\
\text { infecção } \\
\text { (\%) }\end{array}$ \\
\hline B. glabrata F & $\mathrm{BHF}_{4}$ & 20 & 12 & 60 (a) \\
B. glabrata F & $\mathrm{SJF}_{4}{ }^{4}$ & 17 & 2 & 12 (a) \\
B. tenagophiła F & $\mathrm{BHF}_{4}$ & 23 & 0 & 0 \\
B. tenagophila F ${ }_{4}$ & $\mathrm{SJF}_{4}$ & 27 & 7 & 26 (b) \\
\hline
\end{tabular}

(a) diferença significativa $(p=0,002)$

(b) diferença significativa $(p=0,002)$.

Tabela 4 - Infecciosidade de miracídios de S. mansoni das linhagens BH e SJ selecionados e não selecionados frente a moluscos simpátricos não selecionados.

\begin{tabular}{lcccc}
\hline M olusco/Geração & $\begin{array}{c}\text { Linhagem e } \\
\text { Geração do S. } \\
\text { mansoni }\end{array}$ & $\begin{array}{c}\text { Número de } \\
\text { moluscos } \\
\text { utilizados }\end{array}$ & $\begin{array}{c}\text { Número de } \\
\text { moluscos } \\
\text { positivos }\end{array}$ & $\begin{array}{c}\text { Taxa de } \\
\text { infecção } \\
\text { (\%) }\end{array}$ \\
\hline B. glabrata P & BHP & 50 & 22 & 44 (a) \\
B. glabrata P & BHF4 & 50 & 36 & 72 (a) \\
B. tenagophila P & SJP & 59 & 9 & 15 (b) \\
B. tenagophila P & SJF5 & 30 & 4 & 13 (b) \\
\hline
\end{tabular}

(a) diferença significativa $(p=0,004)$.

(b) diferença não significativa $(p=0,807)$ 
B. glabrata selecionada infectou-se de maneira semelhante com miracídios $\mathrm{BH}$ e SJ não selecionados. Entretanto, B. tenagophila selecionada não se infectou com miracídios BH não selecionados (Tabela 2).

Moluscos selecionados B. glabrata e B. tenagophila discriminaram as linhagens de miracídios selecionados, apresentando taxas de infecção maiores quando expostos a miracídios simpátricos (Tabela 3).

A infecciosidade dos miracídios BH selecionados frente ao molusco simpátrico não selecionado foi maior do que a infecciosidade apresentada por miracídios da mesma linhagem, porém não selecionados. Para a linhagem SJ não se observou essa diferença: miracídios SJ selecionados infectaram de maneira semelhante moluscos simpátricos não selecionados (Tabela 4).

\section{DISCU SSÃO E CONCLU SÕ ES}

O equilíbrio da relação hospedeiro-parasita depende da constituição genética dos organismos envolvidos, que condiciona a capacidade fisiológica e metabólica no processo de interação. Conforme sugerido por Schmid-Hempel e Koella ${ }^{17}$ (1994), no binômio molusco-esquistossomo, é aplicável a relação "gene-for-gene", isto é, para cada gene condicionando a susceptibilidade existe um gene específico condicionando a patogenicidade do parasita. A susceptibilidade de B. glabrata e B. tenagophila é controlada geneticamente e herdável através das gerações (Newton ${ }^{10}$, 1953, Richards ${ }^{14}$, 1970; Santana e col. ${ }^{15}$, 1978).

Caracteristicamente, B. glabrata de Belo Horizonte (MG, Brasil) é susceptível ao $S$. mansoni simpátrico (linhagem $\mathrm{BH}$ ), porém resistente ao trematódeo de São José dos Campos (SP, Brasil). Por sua vez, B. tenagophila de São José dos Campos é susceptível à linhagem local (linhagem SJ) resistindo, contudo, à infecção por S. mansoni de Belo Horizonte (Paraense e Corrêa $\left.{ }^{11}, 1963\right)$. Os citados autores sugeriram a existência, de uma adaptação fisiológica entre o molusco e a linhagem local do parasita. Diferenças fisiológicas intraespecíficas têm sido atribuídas para explicar as diferentes taxas de susceptibilidade apresentadas por diferentes amostras de $B$. glabrata. Segundo alguns fatores genéticos do molusco e do parasita estão envolvidos nas variações de comportamento observadas no desenvolvimento do $S$. mansoni no hospedeiro intermediário.

(Files e Cram ${ }^{5}$ (1949), Newton ${ }^{10}$ (1953), Barbosa e Barreto ${ }^{1}$ (1960), Paraense e Corrêa ${ }^{12}$ (1963), Magalhães $^{9}$ (1969) e Schmid-Hempel e Koella ${ }^{17}$ (1994).
Os resultados da Tabela 4 mostraram que miracídios BH não selecionados apresentaram maior taxa de infecção para B. glabrata não selecionada que miracídios SJ não selecionados para $B$. tenagophila não selecionada. A infecção alopátrica nunca foi obtida quando foram utilizadas 10 larvas infectantes para cada molusco.

B. tenagophila caracteristicamente é mais resistente à infecção esquistossomótica, tendo sido atribuído por Lutz ${ }^{7}$ (1923), a este molusco, o nome de Planorbis immunis, como reconhecimento de sua refratariedade. Paraense e Corrêa ${ }^{13}$ (1978), em testes com B. tenagophila, de vinte diferentes localidades submetidas à infecção por $S$. mansoni de São José dos Campos (SJ), mostraram que as taxas de infecção variaram de 0 a 91,5\%. Magalhães ${ }^{8}$ (1969) observou altas taxas de infecção em B. tenagophila de Campinas (SP, Brasil) expostas à linhagem de São José dos Campos (SJ). Dias e col. ${ }^{3}$ (1987) verificaram que exemplares de B. tenagophila de São José dos Campos eram susceptíveis somente às linhagens oriundas de São Paulo, sendo que as taxas de infecção mantiveram-se abaixo de $6 \%$. Alterações na susceptibilidade podem ser obtidas mediante seleção genética dos moluscos (Newton ${ }^{10}, 1953$; Richards ${ }^{14}$, 1970; Santana e col. $\left..^{15}, 1978\right)$. Em resultados apresentados anteriormente Zanotti-Magalhães e col. ${ }^{20}$, (1991), utilizando processo de autofecundação de progenies susceptíveis B. glabrata e B. tenagophila, paralelamente à passagem sucessiva do trematódeo em moluscos selecionados, mostraram crescentes taxas de infecção, evidenciando forte ajuste entre o trematódeo e os vetores.

Em B. tenagophila de SJ e B. glabrata de BH, selecionados geneticamente para o caráter susceptibilidade ao $S$. mansoni, respectivamente das linhagens $\mathrm{SJ}$ e BH , foram observadas larvas íntegras sem reação celular (Guaraldo e col. ${ }^{6}, 1981$ ), ao contrário do que havia sido observado por Coelho ${ }^{2}$ (1957) em B. tenagophila, não selecionada, quando foram descritas larvas degeneradas envolvidas por reação inflamatória amebocitária.

Guaraldo e col. ${ }^{6}$ (1981) não observaram discriminação das linhagnes BH e SJ do trematódeo quando utilizaram B. glabrata e B. tenagophila selecionadas geneticamente para o caráter susceptibilidade. Este resultado, contrário àquele por nós observado, pode ser devido ao processo de seleção dos moluscos então utilizado, quando não se realizou concomitantemente a seleção do parasita.

Os resultados apresentados na Tabela 1 mostraram que a susceptibilidade de moluscos selecionados diante das respectivas linhagens simpátricas não foi alterada pelo processo de seleção das linhagens 
do trematódeo, porém miracídios $\mathrm{BHF}_{4}$ foram mais infecciosos frente a $B$. glabrata não selecionada do que miracídios BHP (Tabela 4).

$B$. glabrata selecionada não discriminou o $S$. mansoni das linhagens $\mathrm{BH}$ e SJ não selecionados (Tabela 2). O processo de seleção de B. glabrata permitiu ampliar sua susceptibilidade frente a um número maior de linhagens do trematódeo (B. glabrata selecionada infectou-se de forma semelhante com as linhagens BHP, SJP e $\mathrm{BHF}_{3}$ de S. mansoni), porém esses moluscos não apresentaram a mesma capacidade de infecção frente a miracídios alopátricos selecionados $\left(\mathrm{SJF}_{4}\right.$ - Tabela 3). Portanto, a passagem sucessiva do $S$. mansoni da linhagem SJ em B. tenagophila selecionada para o caráter susceptilibidade ajustou esta linhagem para esta espécie de molusco. O processo de seleção de B. tenagophila não tornou esta espécie susceptível à infecção com os miracídios BH, mesmo após a seleção desta linhagem através de passagens sucessivas em $B$. glabrata selecionadas.

Estas observações confirmam a excelência de vetor atribuída a $B$. glabrata de Belo Horizonte.

B. tenagophila selecionada discriminou as linhagens selecionadas ou não de $S$. mansoni (Tabela 2 e

\section{REFERÊNCIAS BIBLIO G RÁFICAS}

1. BARBOSA, F. S. \& BARRETO, A. C. Differences in susceptibility of Brazilian strains of Australorbis glabratus to Schistosoma mansoni. Exp. Parasitol., 9:137-40, 1960.

2. COELHO, M. V. Aspectos do desenvolvimento das formas larvais de Schistosoma mansoni em Australorbis nigricans. Rev. Bras. Biol., 17:325-37, 1957.

3. DIAS, L.C.S.; UETA, M.T; GUARALDO, A.M.A. Suscetibilidade de Biomphalaria glabrata, B. straminea e B. tenagophila a diferentes cepas de Schistosoma mansoni. Rev. Inst. Med. Trop. S. Paulo, 29:205-12, 1987.

4. CONCEIÇÃO, M. J. \& COURA, J. R. Comportamento experimental em Biomphalaria glabrata de amostras de $S$. mansoni isoladas de pacientes com diferentes formas clínicas de esquistossomose. [Apresentado ao $19^{\circ}$ Congresso da Sociedade Brasileira de Medicina Tropical. Rio de Janeiro, 1983, p.88].

5. FILES, V. S. \& CRAM, E. B. A study on the comparative susceptibility of snail vectors to strains of Schistosoma mansoni. J. Parasitol., 35:555-60, 1949.

6. GUARALDO, A.M.A.; MAGALHÃES, L.A.; RANGEL, H.A.; PAREJA, G. Evolução dos esporocistos de Schistosoma mansoni Sambon, 1907, em Biomphalaria glabrata (Say, 1818) e Biomphalaria tenagophila (D’Orbigny, 1835). Rev. Saúde Pública, 15:436-44, 1981.
3). A susceptibilidade do binômio B. tenagophila e linhagem SJ só foi alterada pelo processo de seleção do molusco. S. mansoni SJ não se tornou mais infectante pelo fato de ter sido mantido em $B$. tenagophila selecionada (Tabelas 1 e 4).

Valores mais baixos de susceptibilidade na geração $\mathrm{F}_{4}$ (Zanotti-Magalhães e col. ${ }^{20}, 1991$ ), principalmente em $B$. tenagophila, podem ter contribuído para a taxa de $13 \%$ de infecciosidade dos miracídios $\mathrm{SJF}_{5}$ (Tabela 4) frente a $B$. tenagophila não selecionada.

$\mathrm{O}$ fato do $S$. mansoni da linhagem BH selecionado infectar de maneira mais intensa $B$. glabrata não selecionada, quando comparada com $S$. mansoni BH não selecionado (Tabela 4), significa que a maior patogenicidade do parasita selecionado da linhagem BH, já demonstrado em trabalhos anteriores (Zanotti-Magalhães e col. ${ }^{20,21,22}, 1991,1993$, 1995), tem como conseqüência sua maior capacidade de infectar o molusco. Estas observações coincidem com os resultados de Conceição e Coura ${ }^{4}$ (1983), quando verificaram maior produção de cercárias em B. glabrata quando expostas a miracídios oriundos de pacientes com formas clínicas mais graves da esquistossomose.
7. LUTZ, A. Planorbis immunis n.n. Nautilus, 37:36, 1923.

8. MAGALHÃES, L.A. Estudo dos dados obtidos de uma população de Biomphalaria glabrata de Belo Horizonte infectada por Schistosoma mansoni da mesma cidade e de uma população de Biomphalaria tenagophila de Campinas infectada por S. mansoni de São José dos Campos. Rev. Soc. Bras. Med. Trop., 3:195-6, 1969.

9. MAGALHÃES, L.A. Estudo do comportamento da cepa de S. mansoni de Brasília. O Hospital, 77:669-78, 1969.

10. NEWTON, W. L. The inheritance of susceptibility to infection with Schistosoma mansoni in Australorbis glabratus. Exp. Parasitol., 2:242-57, 1953.

11. PARAENSE, W.L. \& CORREAA, L.R. Susceptibility of Australorbis tenagophilus to infection with Schistosoma mansoni. Rev. Inst. Med. Trop. S. Paulo, 5:23-9, 1963.

12. PARAENSE, W.L. \& CORRÊA, L.R. Variation in susceptibility of populations of Australorbis glabratus to a strain of Schistosoma mansoni. Rev. Inst. Med. Trop. S. Paulo, 5:1522,1963

13. PARAENSE, W.L. \& CORRÊA, L.R. Differential susceptibility of Biomphalaria tenagophila populations to infection with a strain of Schistosoma mansoni. J. Parasitol., 64:8226, 1978. 
14. RICHARDS, C.S. Genetic of a molluscan vector of schistosomiasis. Nature, 226:806-10, 1970.

15. SANTANA, J.V.; MAGALHÃES, L.A.; RANGEL, H.A. Seleção de linhagens de Biomphalaria tenagophila e Biomphalaria glabrata visando maior suscetibilidade ao Schistosoma mansoni. Rev. Saúde Pública, 12:67-77, 1978.

16. SAOUD, M. F. A. The infectivity and pathogenicity of geographical strains of Schistosoma mansoni. Trans. R. Soc. Trop. Med. Hyg., 60:585-600, 1966.

17. SCHMID-HEMPEL, P. \& KOELLA, J.C. Variability and its implications for host-parasite interactions. Parasitol. Today, 10:98-102, 1994.

18. ZANOTTI-MAGALHÃES, E. M.; PAIVA, S. M.; MAGALHÃES, L.A.; CARVALHO, J. F. Viabilidade de miracídios de Schistosoma mansoni, obtidos de fezes e de granulomas hepáticos de camundongos experimentalmente infectados com a linhagem BH. Rev. Saúde Pública, 22:47983, 1988.
19. ZANOTTI-MAGALHÃES, E. M.; MAGALHÃES, L.A.; CARVALHO, J. F. Atração miraxonal exercida por Biomphalaria tenagophila selecionada geneticamente para o caráter susceptibilidade. Rev. Saúde Pública, 25:134-8, 1991.

20. ZANOTTI-MAGALHÃES, E.M.; MAGALHÃES, L.A.; CARVALHO, J.F. Relação entre a patogenicidade do Schistosoma mansoni em camundongos e a susceptibilidade do molusco vetor. I. Infectividade da cercária e carga parasitária. Rev. Saúde Pública, 25:359-66, 1991.

21. ZANOTTI-MAGALHÃES, E.M.; MAGALHÃES, L.A; CARVALHO, J.F. Relação entre a patogenicidade do Schistosoma mansoni em camundongos e a susceptibilidade do molusco vetor. II. Número de ovos nas fezes e número e tamanho dos granulomas nas vísceras. Rev. Saúde Pública, 27:412-20, 1993.

22. ZANOTTI-MAGALHÃES, E.M.; MAGALHÃES, L.A.; CARVALHO, J.F. Relação entre a patogenicidade do Schistosoma mansoni em camundongos e a susceptibilidade do molusco vetor. III. Mortalidade, pesos corporal e das vísceras. Rev. Saúde Pública, 29:265-70, 1995. 